\title{
Hi-C-Daze Regimen
}

National Cancer Institute

\section{Source}

National Cancer Institute. Hi-C-Daze Regimen. NCI Thesaurus. Code C161971.

A chemotherapy regimen consisting of high-dose cytarabine, daunorubicin, azacitidine, and etoposide that may be used in the treatment of childhood acute myeloid leukemia (AML). 